D.Gregg Doyle

PhD; Assistant Professor

City and Regional Planning Department

Cal Poly San Luis Obispo

\section{Cal Poly's Bank of America Low-Income Housing Challenge}

Student participation in professional competitions play an important part in the learn-by-doing pedagogy promoted by Cal Poly. Since the early 1990s, the CRP department has spearheaded an interdisciplinary team with participants from other departments to participate in the Bank of America Low-Income Housing Challenge. The author has led the CRP department in the last challenges.

Each year, students from several Cal Poly departments - and across two colleges - band together to compete in the LowIncome Housing Challenge, sponsored by the San Francisco office of the Bank of America. The Challenge pits Cal Poly's team against the likes of UC Berkeley, UC Davis, and Stanford, in a contest to craft the most feasible and creative approach to the housing needs of local households. The purpose, of course, is to help students educate themselves about the realities of developing affordable housing, in order to inspire challenging and rewarding careers in the field.

To that end, students involved on the Bank of America Team come from Architecture, City and Regional Planning, Construction Management, and Finance. Not only does each student learn how to apply the skills and knowledge in his or her field to the development of affordable housing, but team members also learn a great deal about what their colleagues have to contribute to the solution. For many students, this collaboration is the best emulation of their future professional careers that they will experience at Cal Poly.
The 2004 Bank of America Team took on a challenging project, and developed a proposal that would do great things for both the residents and the surrounding community. The project has few pre-determined elements:

- Students must work as a development team to find an appropriately zoned building site;

- A development partner who will construct and operate the buildings; and

- Feasible sources of financing.

The 2004 team found the site and development partner together-the developer father of one teammate was considering acquisition of a site in Old Town Camarillo, Ventura County, and the team decided to take on this challenge.

The resulting project proposed attractively designed affordable housing units above commercial spaces to meet the needs of residents and neighbors alike (see Figure). Since the site is located right on Ventura Boulevard in the historic

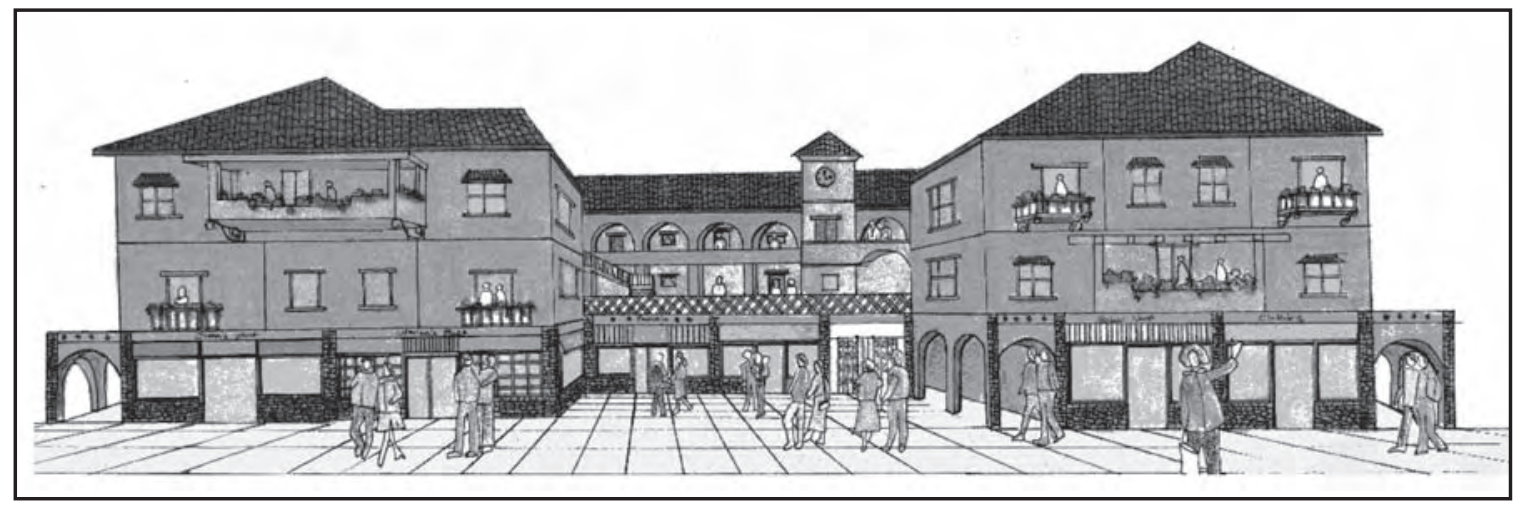

Figure 1.

Rendering from the Low-Income Housing Project 
downtown - and backs up to U.S. Highway 101-it was important to reinforce the existing commercial streetscape and minimize the freeway noise for residents and pedestrians on Ventura Boulevard. In order to maximize buildable area and maintain the streetscape, students proposed parking in 1.5 stories of structured garage below the building, utilizing the natural slope of the site to minimize excavation. As is so often the case, the team learned that parking requirements drive both the size of the building envelope and the feasibility of construction costs. While the 2004 Team did not win the Challenge, we all learned a great deal, and the development partner is currently pursuing acquisition of the site and development of a project based on the Team's ideas.

For 2005, the Bank of America Challenge Team has organized itself into four sub-teams selected from the four departments, and at time of this writing is honing in a project to redevelop an existing residential property owned by the Paso Robles Housing Authority. The team is committed to working on a proposal that is economically feasible, socially responsive, makes the best use of existing buildings, integrates green technologies, and has a significant impact on the local affordable housing problem. You can access out website at http://planning.calpoly.edu/projects/bofa/index.htm and watch for the results from this year's Bank of America LowIncome Housing Challenge jury.

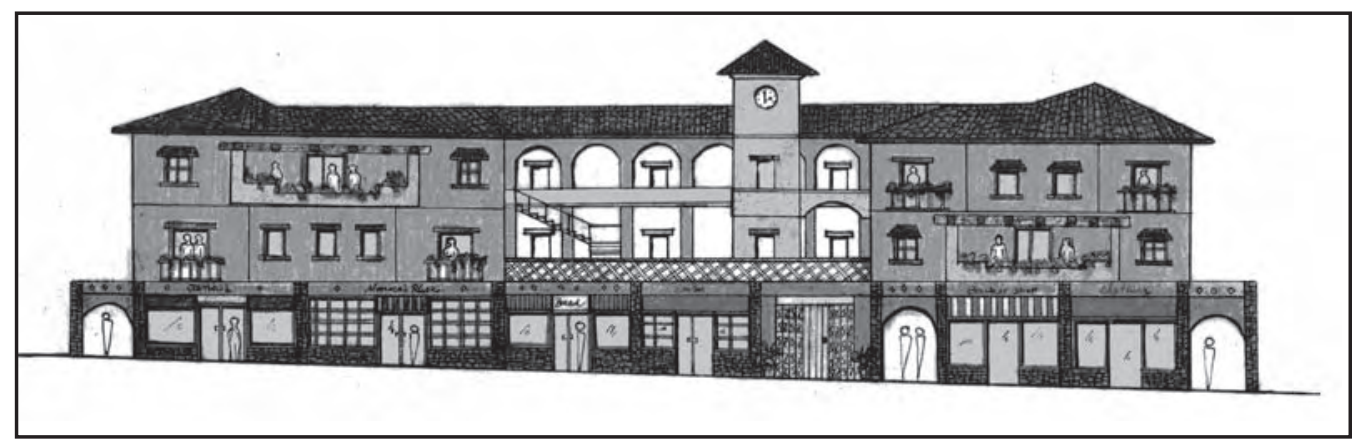

Figure 2. Rendering from the Low-Income Housing Project 